\title{
'Hot-cross Bun Sign' of Multiple System Atrophy
}

\author{
Masaki Takao ${ }^{1}$, Taro Kadowaki ${ }^{2}$, Yutaka Tomita ${ }^{2}$, Yoji Yoshida ${ }^{1}$ and Ban Mihara ${ }^{2}$ \\ Key words: hot-cross bun sign, multiple system atrophy, MRI, neuropathology
}

\section{(DOI: 10.2169/internalmedicine.46.0514)}

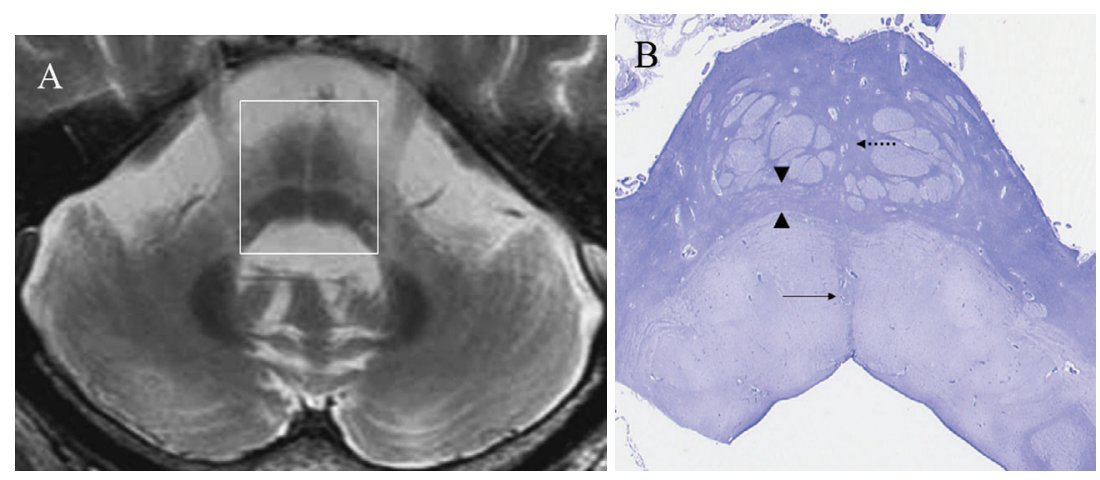

Picture 1.

Well known 'hot-cross bun sign' (cruciform hyperintensity, HCB) may be observed in patients with the cerebellar variant of multiple system atrophy (MSA-C) as well as $\operatorname{SCA} 2$ and $\operatorname{SCA} 3(1,2)$. However, the radiological and neuropathologic correlation of HCB has not been well analyzed (1). A 43-year-old man developed dizziness followed by dysarthria, ataxia and Parkinsonism. He was diagnosed as having MSA-C and died of pneumonia at age 49. Postmortem 3.0T-MRI (GE Medical Systems Signa EXCITE) showed HCB at the level of pons on T2WI (TR4800, TE92) (Picture 1A). To clarify the pathologic basis of HCB, we prepared a histological section at the same plane of MRI (Box in Picture 1A). In addition to the loss of neurons and myelinated fibers at the basis pontis, the section of Holzer stain showed gliosis of the following three regions: 1) middle part of the reticular formation (arrow), 2) the pontocerebellar fiber between the medial lemniscus and pyramidal tract (arrowheads), and 3) the crossing part of the pontocerebellar fibers at the basis pontis (broken line arrow) (Picture 1B). Because astrocytosis increases the local water content (3), we believe that HCB primarily reflects the gliosis rather than only the loss of neurons. We also obtained similar results based on the analysis of a case of SCA2 (data not shown). Our approach may shed light on the study of the clinical-radiological-pathological correlation in neurological disorders.

\section{References}

1. Burk K, Skalej M, Dichgans J. Pontine MRI hyperintensities ("the cross sign") are not pathognomonic for multiple system atrophy (MSA). Mov Disord 16: 535, 2001.

2. Murata Y, Yamaguchi S, Kawakami H, et al. Characteristic magnetic resonance imaging findings in Machado-Joseph disease. Arch Neurol 55: 33-37, 1998.
3. Awad IA, Johnson PC, Spetzler RF, Hodak JA. Incidental subcortical lesions identified on magnetic resonance imaging in the elderly. II. Postmortem pathological correlations. Stroke 17: 10901097, 1986.

\footnotetext{
${ }^{1}$ Department of Cognitive and Intractable Neurological Disorders, Mihara Memorial Hospital, Isesaki and ${ }^{2}$ Department of Neurology, Mihara Memorial Hospital, Isesaki

Received for publication August 11, 2007; Accepted for publication August 30, 2007

Correspondence to Dr. Masaki Takao, takao-jscn@umin.ac.jp

(C) 2007 The Japanese Society of Internal Medicine Journal Website: http://www.naika.or.jp/imindex.html
} 